\title{
TRAJETÓRIAS COGNITIVAS SUBJACENTES AO PROCESSO DE BUSCA E USO DA INFORMAÇÃO: FUNDAMENTOS E TRANSVERSALIDADES
}

\author{
Aida Varela ${ }^{\mathrm{i}}$ \\ Marilene Lobo Abreu Barbosa ${ }^{\text {ii }}$
}

\begin{abstract}
Resumo: Analisam-se as possíveis trajetórias cognitivas decorrentes do processo de busca, recuperação e uso da informação, no âmbito da educação e na inter-relação desta com a ciência da informação, na perspectiva da construção do conhecimento, demonstrando a aplicabilidade dos estudos cognitivos neste processo, abrangendo a relação dos sujeitos intervenientes, no sentido de ampliar a compreensão dos fenômenos informacionais, que ocorrem na dinâmica da transferência da informação, considerando que esta é um ato pedagógico. Apresentamse por contiguidade de conhecimentos e necessidades, os principais representantes das correntes cognitivas educacionais, como substrato aos processos de recuperação, compreensão, reflexão e criticidade essenciais à construção do conhecimento científico, com destaque para o domínio dos vários níveis de leitura e o desenvolvimento de competências para buscar e usar a informação.
\end{abstract}

Palavras-chave: Ciência da informação. Ciências cognitivas. Processos de recuperação e uso da informação. Competência Informacional.

\section{COGNITIVE TRAJECTORIES UNDERLYING THE PROCESS OF SEARCHING AND USING INFORMATION: FUNDAMENTALS AND TRANSVERSALITIES}

\begin{abstract}
The text analyzes the possible trajectories resulting from the cognitive process of searching and using information identified through studies of the intersection of Cognitive Sciences with Information Science, in the perspective of knowledge construction, arguing the applicability of cognitive studies in the search, retrieval and information use, besides the relationship of the persons involved in these processes in order to extend understanding of informational phenomena that occur in the dynamics of information transfer. It presents in contiguity of knowledge and needs, the main representatives of current cognitive education, as a substrate for recovery processes, understanding, critical reflection and essential to the construction of scientific knowledge, especially in the domain of various reading levels and the development of skills to searching and use information.
\end{abstract}

Keywords: Information science. Cognitive sciences. Processes of retrieval and information use. Information Skills.

\footnotetext{
${ }^{i}$ Universidade Federal da Bahia. varela@ufba.br.

ii Universidade Federal da Bahia. amarilene@ufba.br.
} 


\section{INTRODUCÃO}

O manejo da informação, como recurso mediador e estruturante para se chegar ao conhecimento, é não só uma questão de bem-estar social, bem como decorre dos sistemas sociais, políticos e econômicos que estruturam a sociedade contemporânea, baseada em uma economia de mercado efervescente, competitivo e forte, em permanente busca por inovação. Este contexto está ancorado em soluções tecnológicas concebidas na perspectiva de registrar, ordenar e disseminar a informação, proporcionando um novo modelo de acesso e apropriação dos diversos recursos informacionais e um diálogo muito mais interativo entre pares, o que, consequentemente, muda também a dinâmica da produção e difusão do conhecimento. Ao conceituar o que se tem convencionado chamar, neste universo econômico competitivo, de "Regime de Informação", González de Gómez caracteriza esta conjuntura complexa que envolve a informação como:

Um conjunto mais ou menos estável de redes sociocomunicacionais formais e informais nas quais informações podem ser geradas, organizadas e transferidas de diferentes produtores, através de muitos e diversos meios, canais e organizações, a diferentes destinatários ou receptores, sejam estes usuários específicos ou públicos amplos. (GONZÁLEZ DE GÓMEZ, 2002, p.34).

O conhecimento sempre foi reconhecido como fator desencadeante do desenvolvimento, no entanto, é na contemporaneidade que sua produção se intensifica e sua aplicação assume papel preponderante. As necessidades de informação são muitas, refletindo a extensão e a diversidade de preocupações com os acontecimentos e mudanças do mundo externo. Por outro lado, a atuação e a capacidade cognitiva do homem são limitadas, o que o obriga a uma seleção das informações às quais dará atenção.

As necessidades de informação nascem de problemas, incertezas e ambiguidades encontradas em situações e experiências específicas. Tais situações e experiências são as interações de um grande número de fatores relacionados não apenas à questão subjetiva, mas também à cultura, aos limites na execução de tarefas, à clareza dos objetivos e do consenso, ao grau de risco, às normas profissionais, à quantidade de controle, etc. Portanto, não estamos apenas preocupados com o significado da informação, mas sim com as condições, padrões e regras de uso, que tornam a informação significativa para determinados indivíduos em determinadas situações.

O uso da informação consiste nas atividades que realiza o indivíduo para captar a informação e transformá-la em conhecimento, incluindo habilidades intelectuais, como a interpretação, controle e organização do conhecimento, funções inerentes à cognição. É nesta 
perspectiva que o estudo da informação adquire destaque na cultura contemporânea, sendo atinente a diversos campos do conhecimento. A informação é considerada um bem simbólico uma vez que produz, organiza e circula em formato de linguagens, transformada em conhecimento, por meio de processos cognitivos. A decodificação e a interpretação da informação incluem atividades de leitura, de construção de relações, conhecimentos prévios, novos dados, comparação de diferentes pontos de vista e a avaliação.

Os principais teóricos da Psicologia, como Piaget (1977), Wallon (1963), Vygotsky (1979), George Mead (1992) e Bakhtin (1981), além de Bourdieu (1982), Barthes (1992), Bruner (1990), Lotman (1988) e Moscovici (1988), defendem a tese de que o ser humano constrói conhecimento a partir da interação dialética com o contexto sociocultural, sustentada pelos processos de internalização e externalização, que engendram a consciência - a externalização como uma reelaboração da internalização - e para a qual o sistema de signos é especialmente importante, já que se trata da representação do conhecimento (FÁVERO, 2005, 2008).

Tomando como referencial as ideias de Fávero (2005), evidenciam-se alguns aspectos teóricos e conceituais:

- O primeiro refere-se à interação entre os ditames cognitivos e as normas sociais, deslocando a ênfase da díade sujeito/objeto para a tríade sujeito/objeto/o outro, considerando a interação humana como o intercâmbio de significados;

- O segundo é o importante papel da mediação semiótica no processo do desenvolvimento psicológico humano, o que significa a compreensão de que os objetos, assim como as ações humanas, possuem significado sociocultural;

- O terceiro, os efeitos dos sistemas de signos no desenvolvimento psicológico da cognição, nas comunicações individuais e nas maneiras que as práticas das instituições sociais interagem com o funcionamento mental do indivíduo;

- O quarto a consciência de que ações humanas são práticas sociais fundamentadas por conteúdos, assim, tanto os objetos quanto as ações em si mesmos atuam como veículo na mediação dos significados, que integram as representações sociais das áreas do conhecimento, existindo uma interação entre os paradigmas pessoais e os institucionais. 
Com base no exposto, analisam-se os temas informação, mediação, cognição e competências, tomando como marco de referência a interrelação entre a ciência da informação, os estudos cognitivos e as pesquisas educacionais, na perspectiva da construção do conhecimento, demonstrando a aplicabilidade dos estudos cognitivos na busca e recuperação da informação e na relação dos sujeitos intervenientes nestes processos. Refletese sobre a intervenção das teorias cognitivas no processo de construção e desconstrução da organização da informação, analisando o exercício intelectual de apreensão e representação do conhecimento contido em fontes informacionais.

\section{A RELEVÂNCIA dA COGNIÇÃo NA CONSTRUÇÃO DE SIGNIFICADOS NA LEITURA DE MUNDO}

O desenvolvimento do ser humano é um processo de transformação de significados partilhado socialmente. A interiorização do mundo se realiza a partir da interpretação de cada indivíduo, mediante a compreensão de significados. Segundo Vygotsky (1984), o desenvolvimento é um processo dinâmico de transformações de sentidos partilhados inter e intrapsicologicamente.

A construção de significados partilhada evidencia a importância do processo do conhecimento a partir da compreensão do outro e dos sentidos que são elaborados. Os espaços de trocas coletivas de sentidos e afetos, por meio de diálogo, são fontes de novas construções psicológicas, pois criam os processos de internalização, advindos da reflexão, por meio do intercâmbio de experiências que são comunicadas e se convertem em um ponto de encontro entre os indivíduos.

Necessita-se da ciência com consciência trabalhando mente, cérebro, corpo, percepção, informação e emoção. À educação cabe responder às demandas da sociedade da informação, sociedade complexa, a um projeto educativo para a comunidade e para a vida cotidiana, a um significado e sentido partilhados, ao fortalecimento do processo ensinoaprendizagem, ao desejo de participação e desenvolvimento do aluno e da comunidade. Por sua vez, a missão da escola é fazer com que alunos aprendam, tornem-se melhores e mais competentes.

Para isto, o estudo das teorias de aprendizagem assume uma relevância sem igual para os profissionais que trabalham com a organização e disseminação da informação. A área 
dedicada à cognição tem-se mostrado extremamente produtiva e mapeá-la apresenta-se como uma tarefa complexa.

Segundo Axt (1999), mapeando-se a cognição, tomando-se em consideração a visão filosófica, as muitas correntes seriam inseridas nos três paradigmas básicos: o empiricista, o inatista e o apriorista, que remontam à antiguidade grega com Aristóteles e Platão, e são estudados de diferentes formas por inúmeros pensadores: a exemplo da Tabula Rasa, de Locke, as Mônadas, de Leibniz, e a Razão Pura, de Kant, ou a razão prática. Também neste século, surgem novas visões sobre os três paradigmas básicos: a) os estruturalistas organizam suas concepções entre o inatismo/apriorismo e o empiricismo; b) a linguística estruturalista de Saussure, c) a Gestalt de Köhler e Wertheimer; d) a psicanálise, de Lacan; e) a análise do discurs, de Pêcheux; f) a linguística gerativa, de Chomsky; g) a semântica interpretativa, de Fodor; h) o paradigma da auto-organização, que emerge, particularmente neste século, tanto associado aos modelos propostos por biólogos, como Bertalanffy, Piaget, Waddington, e mais recentemente Maturana e Varela, quanto aos modelos cibernéticos, físico-químicos e matemáticos (Wiener, Ashby, Shannon, Prigogine), que começaram a se destacar a partir da década de 50.

Vale a pena ressaltar que o estudo da mente e de seus processos de produção de significações e de conhecimento enfrentam alguns limites disciplinares, segundo as expectativas de cada momento histórico e os rumos que toma a psicologia cognitiva - o seu objeto de pesquisa e as respostas que poderão ser dadas às clássicas indagações sobre a consciência, o conhecimento e as relações entre organismo biológico, sujeito individual e coletividade sociocultural.

De acordo com Del Nero (1997), a discussão relacionada à cognição e à construção do conhecimento é fundamentada nas duas extremidades: 1) no extremo exterior, é focalizada a produção da mente na confluência com a cultura (entre o coletivo e o individual); 2) no extremo interno, a produção da mente é considerada na confluência com o organismo biológico, quando se discute a interdependência mente-cérebro e como se dá o processamento de sinais elétricos nas células cerebrais. Entre dois mundos de naturezas diferentes, a mente funciona como um elo entre si, a organização bio-físico-química e a organização sociocultural e institucional.

Em seus estudos sobre as relações mente-cérebro-cultura, Del Nero (1997, p. 21) considera que “[...] a mente está situada na encruzilhada entre a natureza que selecionou o 
cérebro humano, a linguagem que permitiu a comunicação, a história pessoal que moldou o rosto de cada um e a história coletiva que nos dá padrões médios de ação e juízo".

Observa-se que os estudos da cognição permeiam várias áreas do conhecimento:

a) as ciências humanas e as ciências sociais, que refletem sobre os produtos cognitivos da mente (linguagem, memória, conhecimento, em relação, ou não, com outros produtos mentais como o psiquismo) e que refletem sobre as relações interindividuais entre sujeitos cognoscentes, bem como sobre as relações de cada um com o coletivo sociocultural e institucional no interior do campo mais abrangente da subjetividade de que a cognição é uma parte;

b) as ciências biológicas, que estudam o cérebro e o sistema nervoso como partes do organismo humano responsáveis, no seu conjunto, pela produção da mente;

c) as ciências exatas, pelos estudos relativos aos componentes físico-químicos do sistema nervoso no cérebro, responsáveis por carregar e coordenar a informação, integrá-la de modo a permitir a sua interpretação pelas funções mentais, além dos estudos matemáticos e de engenharia e informática envolvidos com a Inteligência Artificial e a construção de protótipos e a formalização dos modelos para pensar a mente humana.

Rozados (2003) defende a intersecção da Ciência da Informação com as Ciências Cognitivas e afirma que qualquer análise sobre o que é informação leva as ideias de: estruturas cognitivas, atos de conhecer, processos cognitivos e como as pessoas pensam, justificando que há em todas elas uma memória interior, uma visão de mundo, um modelo de conhecimento, um jeito ou um estilo de conhecer as coisas.

Bertran Brookes (1980) considerado o iniciador do enfoque cognitivo na CI, na década de 70, propõe a equação cognitiva para a Ciência da Informação: $K(S)+D(I)=K(S+D S)$ e enuncia que a informação é algo que modifica a estrutura cognitiva de alguém, propondo três aspectos que devem ser entendidos: o que são estruturas do conhecimento $K(S)$; modificações nas estruturas do conhecimento K (S + DS); e quem modifica as estruturas do conhecimento $\mathrm{D}(\mathrm{I})$.

Nos anos 90, a hegemonia cognitiva é questionada. Birger Hjorland levanta questões sobre a exclusão da cognição dos contextos sociais e culturais em que participa o indivíduo e 
declara incorporar na investigação psicológica uma perspectiva social, cultural e histórica mais ampla. (HJ0RLAND, 1995.)

A tendência sócio-cognitiva não é apenas uma crítica ao cognitivismo ortodoxo, e sim uma nova maneira de assumir a visão cognitivista, integrando este enfoque ao universo sociológico e cultural, retirando a atenção da estrutura individual do conhecimento "domínios do discurso", para as comunidades que produzem, partilham e consomem conhecimento. (HJORLAND, 1995, p.51.)

O domínio do discurso ou do conhecimento é um espaço científico ou profissional com estruturas únicas de comunicação, tipos únicos de documentos e combinações informacionais específicas. Para tanto, para identificar o domínio do discurso e a comunidade profissional do conhecimento, há que se privilegiar o contexto que o produz. (HJORLAND, 1995.)

Um dos expoentes do enfoque cognitivo no estudo de usuários é o sense-making, introduzido pela norte-americana Brenda Dervin (1986), que elaborou uma proposta teórica e metodológica, propondo uma separação entre o ser humano e os sistemas de informação. $\mathrm{O}$ sense-making entende a informação como um dado incompleto, ao qual o indivíduo atribui sentido a partir da intervenção de seus esquemas mentais interiores. A busca da informação é orientada por uma falta, uma falha na estrutura de conhecimento do usuário e caracteriza-se por redefinir os turnos de busca ou de um problema a partir do usuário, o foco de interesse é o usuário.

O sense-making constitui-se de quatro elementos: a situação no tempo e espaço; a lacuna que identifica a situação desejada; o uso, o resultado; a ponte como meio de preencher a lacuna, a necessidade do usuário.

Carol Kuhlthau (1991), que estudou padrões do processo de busca e uso de informação, explorando a visão construtivista do aprendizado, sob uma perspectiva fenomenológica, e outros estudiosos da Teoria da Significação defendem que a estrutura cognitiva se reestrutura durante a aprendizagem significativa porque o processo de apropriação de conhecimento é dinâmico e, portanto, as estruturas de conhecimento de um indivíduo estão permanentemente sendo alteradas.

Pela abordagem da Significação de Kuhlthau (1991) o processo de busca de informação é uma atividade construtivista do usuário para encontrar significado, a partir da informação, a fim de ampliar seus conhecimentos sobre determinado problema ou assunto. A base teórica de sua teoria repousa sobre a teoria do construto pessoal, que descreve a 
experiência afetiva dos indivíduos envolvidos no processo de construção do significado proveniente da informação que encontram.

Os seres humanos estão em um movimento permanente de aprendizagem por meio de construções e transformações que realizam em si, modificando continuamente o seu modo de conhecer, refletir, proceder e se comportar, como consequência de sua interação atenta com o mundo.

\section{REPRESENTANTES DAS CORRENTES COGNITIVAS EDUCACIONAIS}

Com este enfoque, evidencia-se o significado dos estudos das correntes cognitivas, como bases pedagógicas para a formação de profissionais que trabalham com a organização e disseminação da informação e com a leitura, na perspectiva de promover a transferência da informação, fenômeno que envolve o conhecimento e a compreensão de processos linguísticos, mentais e de aprendizagem dos indivíduos, a partir dos interesses e necessidades destes indivíduos e do contexto em que se situam, condição inerente às diferentes etapas da evolução biológica. Este profissional deve entender, ainda, como os aspectos culturais, políticos, econômicos e sociais de uma nação influenciam nos componentes pedagógicos e didáticos, na formação de bons leitores e usuários da informação.

Diversas classificações podem ser usadas como referência para categorizar as teorias psicológicas e suas respectivas influências no campo da cognição e da educação. Uma possível classificação é a dos modelos do comportamentalismo e da teoria do processamento de informação.

Skinner (1979) é reconhecido como o nome mais importante da corrente comportamentalista, para o qual os comportamentos são aprendidos e mantidos por meio de reforços produzidos pelo meio ambiente, entendido como fator determinante do desenvolvimento e da aprendizagem, enquanto que as estruturas cognitivas são reflexo de estruturas existentes fora da pessoa, no mundo físico.

Resultante das influências do desenvolvimento tecnológico, da linguística, da antropologia surge a teoria do processamento da informação, nos Estados Unidos, na década de 1950, motivada pelos crescentes estudos sobre o computador, quando muitos cientistas discutem o processamento da informação pelo cérebro humano. 
Para Pozo (2005) há duas tendências da psicologia cognitiva: o modelo associacionista e o modelo organicista. O modelo associacionista caracteriza-se por ser mecanicista, quando apresenta o organismo a partir de seus mecanismos de funcionamento e os analisa de forma pontual e estática, configurando-se, também, como elementarista, por entender que os mecanismos são organizados por partes elementares, iniciando-se por pequenas partes que vão sendo associadas; e é ainda considerado um modelo isomórfico, que compreende o organismo como aquele que percebe, aprende e forma conceitos, por meio da relação direta que estabelece com os estímulos do mundo.

Já o modelo organicista parte do princípio de que o organismo é organizado por princípios de mudança e alteração constantes. Desse modo, o ser humano é compreendido como um todo e, além disso, os processos de mudança e a formação de estruturas internas são provenientes de reestruturações que nele ocorrem. Ademais, é um modelo holístico, pois analisa o todo e considera que o organismo evolui de forma qualitativa, de acordo com as mudanças ocorridas em sua estrutura e, ao mesmo tempo, heteromórfico, por compreender que o organismo assimila o mundo de acordo com as capacidades de sua própria estrutura interna e não de forma neutra e direta em relação aos estímulos do mundo. Para esse modelo, o organismo altera, seleciona e focaliza os estímulos de acordo com leis internas de seus mecanismos e de sua estrutura cognitiva.

A concepção de aprendizagem do modelo associacionista fundamenta-se, portanto, na associação de elementos básicos, enquanto o modelo organicista fundamenta seu princípio de aprendizagem na reestruturação dos esquemas de conhecimento da estrutura cognitiva.

Com relação às correntes ligadas ao modelo organicista, apesar das diferenças entre elas, podem ser mencionadas a Gestalt, o construtivismo e a abordagem sócio-histórica. Gestalt é uma palavra alemã que significa "forma", "estrutura" ou "configuração". Wolfgang Kohler, em seus experimentos, descobriu que toda aprendizagem consistia na reorganização perceptiva ou percepção do todo da situação-problema, o que ele chamou de insight.

A Gestalt afirma que o organismo tem como foco o estudo da estrutura interna, e que só é possível entendê-lo quando se considera a existência de um todo maior (sua estrutura) que fundamenta a interação dos elementos, ou seja, quando a totalidade da estrutura ultrapassa a simples soma de suas partes. Explica-se o processo mental pelas relações existentes entre as partes e não pelas partes isoladas. Segundo os gestaltistas, a reestruturação se efetua por insight ou - compreensão súbita - do problema. 
A abordagem sócio-histórica de Vigótski (1984) baseia-se na ideia central de que o ser humano cresce pela interação social e, neste processo, o desenvolvimento cognitivo mantém estreita relação com a aprendizagem. O desenvolvimento das funções psíquicas do indivíduo interage continuamente com a aprendizagem, com a apropriação do conhecimento produzido pela humanidade e as relações que estabelece com seu meio.

Para Vigótski (1984), desenvolvimento cognitivo e aprendizagem constituem uma unidade. A aprendizagem, quando significativa, estimula e desencadeia o avanço do desenvolvimento de operações cognitivas para um nível maior de complexidade que, por sua vez, serve de base para novas aprendizagens. Fazem parte do universo teórico do autor conceitos como: zona de desenvolvimento proximal, ferramentas psicológicas, mediação, internalização, entre outros. A inteligência, para Vigótski (1984), desenvolve-se graças a certas ferramentas (instrumentos) psicológicas que o sujeito encontra em seu ambiente, entre as quais a linguagem, considerada fundamental. Para ele, o que nos torna humanos é a capacidade de utilizar instrumentos simbólicos.

O fenômeno psíquico da internalização do sujeito é básico para entender o desenvolvimento das funções psicológicas superiores proposto por Vigótski (1984), funções criadoras da personalidade, da consciência individual e social, tendo como processos fundamentais à mediação e à linguagem. A atividade prática em que se envolve o sujeito seria interiorizada em atividades mentais, cada vez mais complexas, graças às palavras, fonte de formação conceitual e do processo de internalização.

Segundo Vigótski (1984), todo conhecimento é uma produção cultural diretamente relacionada com a linguagem. É por meio da linguagem que se dá a interiorização dos conteúdos, pois ela faz com que a natureza social das pessoas se torne, também, sua natureza psicológica. Para o autor, a palavra se constitui como rico instrumento para transmitir a experiência histórica da humanidade. Todo ser humano, inserido em uma realidade sóciohistórica, apenas adquire a condição humana se for, em sua relação com o mundo, mediado por instrumento de sua cultura - signo, palavra, símbolo. O conhecimento é, portanto, uma produção cultural, diretamente relacionada com a linguagem e com a interação social.

Além dessas ferramentas, há uma vasta área da mais alta ordem de mediadores simbólicos que incluem linguagens natural e artificial, discursos e sistemas culturais de diferentes épocas e nações. Um dos objetivos de Vigótski (1984) foi desenvolver uma tipologia dos processos mentais superiores, a qual se reflete na transição histórica de um sistema de ferramentas psicológicas para outro. 
Para explicar a relação que se estabelece entre desenvolvimento e aprendizagem, Vigótski (1984) formulou os conceitos de zona de desenvolvimento real, zona de desenvolvimento proximal e zona de desenvolvimento potencial. A zona de desenvolvimento real é o nível de desenvolvimento das funções mentais do indivíduo que se estabelecem como resultado de certos ciclos de desenvolvimento já completados, ou de um processo de desenvolvimento cognitivo específico. A zona de desenvolvimento proximal é a distância entre o nível de desenvolvimento real, que se costuma determinar com a solução de problemas de forma independente, e a zona de desenvolvimento potencial determinado, com a solução de problemas sob a orientação de outro indivíduo ou em colaboração com companheiros mais capazes. A área de desenvolvimento proximal compreende funções mentais que estão em estado de formação.

A mediação é a ação que se interpõe entre sujeito e objeto de aprendizagem, sendo a palavra de fundamental importância. Aprender a comunicar-se, a compreender os outros, a entender regras, a compreender que o outro pode ter um ponto de vista diferente, a compreender expressões faciais ou outras expressões de emoção, requer funções cognitivas superiores, como: decodificar signos, gestos, sons, palavras, combinar fontes de informação, levantar e analisar hipóteses, entre outras funções cognitivas.

Na concepção de Vygotsky (1984), os mediadores são instrumentos que transformam a realidade em vez de imitá-la; sua função não é adaptar-se passivamente às condições ambientais, mas modificá-las ativamente. Vygotsky (1984) diferencia duas categorias de instrumentos em função do tipo de atividade. O tipo mais simples de instrumento seria a "ferramenta", que atua materialmente sobre o estímulo, modificando-o. O outro tipo de instrumento mediador, de diferente natureza, que produz uma atividade adaptadora diferente, além de proporcionar ferramentas, é a cultura que está constituída fundamentalmente por sistema de "sinais" ou símbolos que medeiam nossas ações.

O sistema de sinais utilizado com maior frequência é a linguagem falada, porém existem muitos outros sistemas simbólicos que permitem uma atuação sobre a realidade. Ao contrário das ferramentas, o sinal não modifica materialmente o estímulo, mas modifica a pessoa que o utiliza como mediador e, definitivamente, atua sobre a interação dessa pessoa com seu meio. Ainda segundo Vygotsky (1984), os instrumentos de mediação, inclusive os sinais, são proporcionados pela cultura, pelo meio social, contudo a aquisição dos sinais não consiste somente em torná-los do mundo social externo, mas é necessário interiorizá-los, o que exige uma série de transformações. 
Os estudos de Piaget são relevantes para que se entenda a atual psicologia do desenvolvimento cognitivo. Como enfatiza Flavell (1985), a teoria piagetiana do conhecimento, baseada em uma tendência ao equilíbrio cada vez maior entre os processos de assimilação e de acomodação, tem como objetivo explicar não somente como conhecemos o mundo em determinado momento, mas também como nosso conhecimento, a respeito do mundo, muda.

Usando uma metáfora tomada da Biologia, Piaget (1970) diz que a "assimilação é a integração de elementos exteriores e estruturas em evolução ou já acabadas no organismo". Assim, em termos psicológicos, a assimilação seria o processo pelo qual o sujeito interpreta a informação que provém do meio, em função dos esquemas ou estruturas conceituais de que dispõe.

Se antes de Feuerstein (1980), com Piaget (1987), o baixo rendimento cognitivo e o fracasso no processo de aprendizagem eram - e ainda são - vistos como frutos da imaturidade biológica da estrutura cognitiva do indivíduo, estes passaram a ser vistos como consequência da falta de interação social, o que Feuerstein denomina experiência de aprendizagem mediada.

Os estudos e pesquisas de Jean Piaget (1971) registraram, sob a ótica construtivista, alterações sofridas pelo organismo humano em processo de desenvolvimento. A Psicologia Genética Piagetiana centraliza-se na operatividade cognitiva do indivíduo, segundo as leis da Lógica, da Física, das Leis Formais da Natureza, portanto, o logicismo piagetiano permite a descrição das estruturas mentais implícitas na resolução de problemas.

Para Piaget, a estrutura cognitiva deve ser concebida como um processo em transformação e entender as transformações qualitativas, pelas quais passa a mente humana, é entender o próprio estado da mente (Piaget e Inhelder, 1986). Segundo Piaget, a estrutura cognitiva é construída em etapas e cada etapa incorpora as anteriores, dando-se a construção do conhecimento pela ação recíproca e interativa do sujeito com os objetos (meio). A estrutura mental e o conhecimento são construídos em uma relação dialética entre a maturação biológica e o ambiente.

Discípulo de Piaget, Feuerstein (1980), por meio da Teoria da Modificabilidade Cognitiva Estrutural, averigua como o sujeito chega à solução do problema, empregando a analogia do computador - entrada, processo e saída - e propõe o mapa cognitivo como ferramenta de análise do ato mental. Esse mapa demonstra como o sujeito aprende e, o mais importante, permite-lhe aprender a aprender. 
Construir é interagir. O homem se constrói pelo relacionamento - o homem relacionado é sujeito e agente da história. A interação social é uma forma privilegiada de acesso à informação e ao objeto do conhecimento. Feurstein, através de seus estudos, inicialmente com crianças vítimas do Holocausto, depois com imigrantes em geral e hoje com comunidades escolares, com indústrias e outros segmentos sociais, Feuerstein (1980) vem consolidando o paradigma de que a inteligência, com sua característica de plasticidade, é incrementada pela interação social.

Neste aspecto, Vigótski (1984) ressalta as relações culturais de mediação das estruturas psicológicas. O fator decisivo no desenvolvimento não recai sobre o indivíduo, sujeito dos processos de construção intelectual, mas sobre os processos de mediação das estruturas cognitivas e linguísticas. A teoria de Vigótski (1984) não enfatiza apenas a ação do sujeito epistemológico autônomo, mas precipuamente a mediação cultural, ou a ação dos outros sujeitos na construção psicológica individual.

Vigótski defende que o desenvolvimento da estrutura cognitiva do ser humano implica uma relação muito estreita entre maturação e cultura. A cultura modela a estrutura cognitiva humana porque esta o permite. Para Feuerstein (1980), a modificabilidade é um fator tanto biológico quanto cultural, o que o remete a Vigótski. O conceito de modificabilidade implica uma estrutura cognitiva permeável aos estímulos culturais e torna cada indivíduo único, imprevisível, capaz de superar suas condições atuais.

Feuerstein (1980) parece apropriar-se da ênfase vigotskiana da mediação cultural dos processos psicológicos, enfatizando epistemologicamente a necessidade e importância da ação mediada nos processos de construção intelectual. Percebe-se que Feuerstein e Vigótski desenvolveram suas teorias sob forte influência de Piaget. Contudo, começaram a perceber que certos aspectos da diretriz piagetiana poderiam ser enriquecidos. Para Vigótski (1984), a insatisfação estava no individualismo epistemológico da teoria de Piaget e na negligência da mediação social. Para Feuerstein (1980), havia a questão dos mecanismos concretos da aprendizagem em relação à mediação de outro ser humano.

- $\quad$ Em síntese, Piaget (1971), na ótica construtivista, defende que a estrutura mental e o conhecimento são construídos numa relação dialética entre a maturação biológica do homem e o ambiente. Já Vygotsky (1991), na visão sócio-histórica, declara que todo ser humano, inserido numa realidade, adquire a condição humana se for em sua relação com o mundo, mediado por instrumentos de sua cultura, interagindo socialmente. Feuerstein (1980), sob a ótica da modificabilidade cognitiva estrutural, por meio da mediação, defende que a 
interação humana impulsiona o desenvolvimento da estrutura cognitiva e potencializa a modificabilidade.

Segundo Ausubel (1978), para que aconteça uma aprendizagem significativa, é necessário que o material que se deve apreender e o sujeito aprendente atendam determinadas condições. Em relação ao material, é necessário que não seja arbitrário, isto é, que possua significado em si mesmo. Um material possui significado lógico ou potencial se seus elementos estão organizados e não somente sobrepostos. A maior parte das aprendizagens significativas é subordinada, isto é, a nova ideia aprendida se encontra hierarquicamente subordinada a uma ideia preexistente.

Uma das diferenças essenciais entre as duas concepções de aprendizagem analisadas, o associacionismo e o organicismo, reside na natureza das mudanças que elas estudam. As teorias associacionistas, em suas mais diversas variantes, ocupam-se de mudanças contínuas, mensuráveis e, portanto, quantificáveis, que ocorrem em consequência da prática acumulada sob determinadas condições. As teorias organicistas ou da reestruturação ocupam-se das mudanças produzidas na organização das estruturas cognitivas, em consequência da interação de estruturas e objetos aos quais são aplicadas.

A obra de Paulo Freire (1980) constitui-se numa tentativa de recuperar e proporcionar conceitos e instrumentos metodológicos do estruturalismo genético e da razão dialética, mostrando sua aplicabilidade ao processo pedagógico. No conjunto de sua obra, podem ser destacados alguns elementos ontológico-epistemológicos, entre eles o conceito de "educação dialógica" versus "educação bancária". $\mathrm{Na}$ "educação bancária", duas estruturas se confrontam - a do educador que sabe e comunica e a do educando que não sabe e aprende - e na educação dialógica, dois processos de estruturação gnoseológica interagem, um ensinando/aprendendo com o outro e ambos construindo o conhecimento do mundo.

Freire $(1979,2002)$ ressalta a importância e a necessidade de se entender a existência humana a partir de sua substancialidade, ou seja, o reconhecimento de todos os homens como verdadeiros sujeitos históricos. Os atributos dos seres humanos não podem, assim, sobrepujar o reconhecimento da existência humana: a sua presença no mundo como sujeito.

Faz-se necessário reconhecer a humanização não apenas como viabilidade ontológica, mas como realidade histórica. Humanização e desumanização estão inseridas na história, em um contexto real, concreto e são possibilidades dos homens como seres inconclusos e conscientes de sua inconclusão. 
Para Freire (1979), o diálogo assume papel fundamental na constituição da consciência, pois esta é essencialmente dialógica, pelas relações estabelecidas com os outros e com o mundo. No diálogo, a tomada de consciência se transforma em conscientização. Para Freire, é no diálogo e na comunhão que os homens e as mulheres se conscientizam. O diálogo é a chave para a conscientização dos homens, das mulheres e do mundo.

Segundo Freire (1985) a tomada de consciência constitui o primeiro momento de apreensão da realidade. Esse conhecimento existe porque os seres humanos são e estão "situados" e "datados", e os homens são espectadores "com" e "no mundo". Essa tomada de consciência não significa ainda a consciência crítica, quando há maior intensidade do desenvolvimento crítico. Por esta razão, a consciência crítica implica ultrapassar a esfera espontânea da apreensão da realidade para uma posição crítica. Por meio dessa crítica, a realidade passa a ser reconhecida como um objeto diante do qual o homem assume uma posição epistemológica: o homem em busca do conhecimento.

Diante do exposto, a transferência e a aplicabilidade dos princípios do estruturalismo genético de Piaget, da teoria sócio-histórica de Vigotsky, da TMCE e da EAM de Feuerstein, e os enfoques de consciência e autonomia de Paulo Freire merecem destaque como facilitadores das condições da estrutura lógica dos que lidam com informação e educação, os quais devem ser co-responsáveis pelo desenvolvimento de competências características dessa sociedade em mudança, destacando-se entre elas as competências cognitivas e informacionais, temas em discussão no contexto mundial.

\section{TRAJETÓrias COGNITIVAS SUBJACENTES AO PROCESSO DE BUSCA, RECUPERAÇÃO E APROPRIAÇÃO DA INFORMAÇÃO PELO SUJEITO}

A busca de informação é um processo de construção de conhecimento e significado. A formulação de um foco ou de um ponto de vista é o ponto de mutação do processo de busca, resultante de um ato de reflexão - relacionar e interpretar as informações. A consciência, os sentidos, a percepção, a atenção, a memória, o pensamento, o raciocínio, a formação de conceitos e a inteligência são fatores intervenientes e subjacentes ao processo ensino e aprendizagem. Assim o leitor-usuário, na trajetória de busca e recuperação da informação, realiza tarefas cognitivas de seleção, análise, síntese, comparação, organização e escrita, de 
acordo com sua estrutura cognitiva, seus interesses e necessidades, seus conhecimentos prévios e suas condições internas e externas.

Todo conhecimento constitui, ao mesmo tempo, uma tradução e uma reconstrução, a partir de sinais, signos, símbolos, sob a forma de representações, ideias, teorias, discursos. A organização dos conhecimentos é realizada em função de princípios e regras que não cabe analisar aqui; comporta operações de ligação (conjunção, inclusão, implicação) e de separação (diferenciação, oposição, seleção, exclusão). O processo é circular, passando da separação à ligação, da ligação à separação, e, além disso, da análise à síntese, da síntese à análise. Ou seja, o conhecimento comporta, ao mesmo tempo, separação e ligação, análise e síntese.

Como nosso modo de conhecimento desune os objetos entre si, precisa-se conceber o que os une. Como ele isola os objetos de seu contexto natural e do conjunto do qual fazem parte, é uma necessidade cognitiva inserir um conhecimento particular em seu contexto e situa-lo em seu conjunto. De fato, a psicologia cognitiva demonstra que o conhecimento progride menos pela sofisticação, formalização e abstração dos conhecimentos particulares do que, sobretudo, pela aptidão a integrar esses conhecimentos em seu contexto global. A partir daí, o desenvolvimento da aptidão para contextualizar e globalizar os saberes torna-se um imperativo da educação.

Buscar e usar a informação constitui-se em competências cruciais na sociedade da aprendizagem, envolve a busca ativa ou passiva da informação, planejamento, estratégias e motivação para atingir objetivos, monitoração de estratégias, conhecimento e definição de canais ou fontes de informações potenciais, competências para usar tecnologias da informação e avaliação desse processo.

O uso da informação compõe-se de atividades em que o indivíduo se engaja para apreender a informação e transformá-la em conhecimento. Compreendem habilidades intelectuais como decodificação, interpretação, controle e organização do conhecimento. A decodificação e a interpretação por sua vez incluem atividades de leitura, estabelecimento de relações e conhecimento prévio e as novas informações, comparação de vários pontos de vista e avaliação. Controle e organização relacionam-se propriamente à organização da informação por meio de uso de instrumentos cognitivos, como recursos, esquemas, mapas conceituais e elaboração de textos. 


\subsection{A Leitura Como Recurso de Apreensão do Conhecimento}

A leitura é uma atividade intelectual complexa, na qual a mente estabelece uma rede associativa intricada e ilimitada, que agrega dispositivos cognitivos, linguísticos, habilidades técnicas e envolvimento emocional, exercendo uma função determinante na aquisição de conhecimento pelo sujeito.

A compreensão completa de textos envolve os processos de recuperar informações, construir uma compreensão geral ampla, desenvolver uma interpretação; e refletir sobre o conteúdo de um texto e avaliá-lo. Devido a toda essa complexidade, torna-se indispensável esclarecer alguns pontos: o caráter processual e progressivo da compreensão que garante a possibilidade de passar a estruturas sempre mais profundas na abordagem do texto, enquanto as habilidades de base têm a tendência a constituir-se em meros automatismos. Os cinco processos acima citados podem ser percebidos em quatro características: focalizar trechos independentes do texto, focalizar trechos específicos do texto, focalizar conteúdo e focalizar a estrutura.

Para recuperar a informação o leitor precisa percorrer a trajetória do investigar, procurar, localizar e selecionar. Na maior parte das vezes, o processamento envolvido ocorre no nível de frases, embora em alguns casos a informação esteja contida em uma ou mais frases ou em parágrafos diferentes.

No processo de construção de uma compreensão geral ampla o leitor tem de demonstrar uma compreensão inicial, identificando o tópico ou a mensagem principal, o objetivo geral ou a utilização geral do texto, para isto há que se estabelecerem relações entre as partes do texto, deduzir o tema a partir da repetição de uma categoria particular de informações. Para selecionar a ideia principal implica estabelecer uma hierarquia, escolhendo a mais geral e predominante, ou seja, distinguir entre ideias centrais e detalhes secundários, ou reconhecer o resumo do tema principal em uma frase ou em um título.

No desenvolvimento de uma interpretação exige-se que os leitores ampliem suas impressões iniciais, de forma a desenvolver uma compreensão mais específica ou mais completa sobre o que foi lido. Nessa categoria é exigida a compreensão lógica: os leitores precisam processar a organização da informação no texto. Para fazê-lo, devem demonstrar sua compreensão sobre coesão. Para chegar a esta fase, faz-se necessário comparar e contrastar informações, fazer inferências e identificar e listar evidências de apoio. 
Van Dijk (1996, p. 16) interpreta um enunciado a partir da compreensão de acontecimentos reais ou eventos discursivos, e esse ato envolve a construção de uma representação mental, de que fazem parte “[...] não somente o processamento e interpretação de informações exteriores, mas também a ativação e uso de informações internas e cognitivas do processo de construção". De acordo com Ducrot (1987, p. 89) “[...] o enunciado é um conjunto de atos de fala (atos ilocutórios) que o locutor pretende realizar através de uma enunciação; e a frase como uma entidade linguística abstrata, idêntica a si mesma em suas mais diversas ocorrências".

A reflexão sobre o conteúdo de um texto e sua avaliação demandam que o leitor relacione a informação encontrada em um texto a conhecimentos provenientes de outras fontes. Os leitores devem também avaliar as afirmações do texto em comparação com o próprio conhecimento do mundo. Os leitores devem recorrer a evidências de apoio contidas no texto e compará-las a outras fontes de informação, utilizando conhecimento geral e específico, assim como capacidade de raciocínio abstrato.

Refletir sobre a forma de um texto e sua avaliação exige que os leitores se distanciem, considerem o texto objetivamente e avaliem sua qualidade e adequação, implicando o conhecimento de estrutura de texto, gênero e registro. Na observância desses processos, o $\operatorname{OECD}$ (2007, p. 46) partiu da seguinte definição: “Alfabetização em leitura é a capacidade de compreender textos escritos, utilizá-los e refletir sobre eles, de forma a atingir objetivos próprios, desenvolver conhecimentos e o próprio potencial, além de participar ativamente da sociedade".

Neste sentido, alfabetização em leitura envolve decodificação e compreensão literal, compreensão e utilização de informações escritas para uma variedade de objetivos bem como a reflexão sobre elas, contando para isso com o leitor ativo e interativo ao extrair significados de textos escritos.

Apesar da demonstração dos processos necessários para se chegar a um autêntico domínio de leitura, ressalta-se que os esquemas cognoscitivos são particulares a cada indivíduo, construídos pelas experiências vivenciadas. As conexões entre os conhecimentos adquiridos ao longo dos anos vão sendo estruturadas continuamente, de uma forma que é particular a cada indivíduo.

Justifica-se, portanto, a expansão do movimento da information literacy, na medida em que está associado à qualificação do processo ensino-aprendizagem, incentivando a leitura e a pesquisa, procurando formar pessoas criativas e autônomas na busca do conhecimento. 
Neste contexto, percebe-se uma mudança de paradigma do modelo centrado na informação, para um modelo centrado no sujeito/usuário: investiga-se o propósito do uso e como esse uso efetivamente contribui para atender as necessidades do usuário. Parte-se do princípio de que quanto melhor se entendem os processos humanos envolvidos na base da informação, melhor poderão ser os sistemas de recuperação e interpretação de textos, reflexão e avaliação da informação para o usuário.

Cabe destacar que o bibliotecário, nas atividades de promoção da leitura e formação de leitores-usuários, desempenha funções docentes e, nesse sentido, prescinde de bases pedagógicas, que lhe tornem proficiente no ofício de bibliotecário-educador, quando atua em processos de formação de pessoas. Neste caso, lhe são requeridas algumas habilidades e destrezas, a exemplo de criatividade, capacidade de comunicação, iniciativa, gestão e liderança, prudência e ousadia ao mesmo tempo, bem como possuir pensamento crítico e analítico; ser capaz de identificar as oportunidades de êxito; e, consequentemente, ser capaz de inovar. O profissional formador deve imergir em áreas como filosofia da educação, psicologia educacional e de aprendizagem, sociologia da educação, inovações metodológicas, tanto na área pedagógica como no âmbito da leitura e na formação de usuários, bem como dominar o manejo de ferramentas computacionais e das estratégias de ensino; estes elementos lhe proporcionarão, também, maturidade para interagir com outros partícipes na formação de leitores.

Assim, preparado com alicerces pedagógicos fortes, o bibliotecário, pelo menos em tese, está apto a atuar, com conhecimento de causa, na capacitação do leitor-usuário, ampliando seu nível formativo, estimulando-o a desenvolver as habilidades básicas de pensar, observar, compreender, analisar, sintetizar, resolver problemas etc., habilidades estas que conferem autonomia ao sujeito diante do mundo.

\subsection{Competências: ferramentas necessárias para a operacionalização dos processos cognitivos}

Nos anos 80, a concepção de competência em informação teve ênfase instrumental, voltando-se para a capacitação dos profissionais, para o uso de tecnologias, em especial, o computador. Em 1987, destaca-se o trabalho da Karol Kuhlthau sobre busca e uso da informação, sugerindo a integração de competências informacionais ao currículo escolar, no intuito da apropriação das tecnologias pelos estudantes, para acessar informações. Kuhlthau 
(1996) definiu a competência em informação como um modo de aprender, enfatizando a noção de processo cognitivo, construindo o que se convencionou chamar de modelo alternativo centrado no usuário. A competência em informação abrange o aprendizado ao longo da vida e a aplicação das habilidades informacionais no dia-a-dia.

Em 1989, o Presential Committee on Information Literacy, da American Library Association (ALA) observou que o desenvolvimento de competências informacionais, pelo sujeito, está associado às habilidades de localizar, avaliar e usar efetivamente a informação a partir de uma necessidade. Na verdade, a competência informacional se concretiza na internalização da trajetória do 'saber como aprender, como o conhecimento é organizado, como encontrar a informação e como usá-la' de modo claro, para que outros aprendam a partir dela.

O essencial é que o usuário tenha condições para identificar sua necessidade informacional; conheça e domine os métodos e as estratégias de busca e recuperação da informação utilizando tecnologias; adquira o controle sobre recursos e fontes de informação ao desenvolver suas habilidades e conhecimentos na gestão da informação; reconheça a informação pertinente e adequada para a necessidade detectada, transformando o conhecimento e ferramentas para a tomada de decisões; ou seja, que o usuário internalize atitude crítica, analítica e reflexiva, indispensável para a investigação e para a aplicação em sua vida pessoal e social, bem como na geração de conhecimento.

Diante da recorrência desta temática, outras instituições veem buscando definir uma série de princípios gerais, critérios e normas que permitam identificar o usuário alfabetizado em informação. Destaca-se, dentre elas, Associação Americana de Bibliotecários Escolares AASL, que estabelece três categorias e dentro de cada uma delas, critérios com alguns indicadores, isto é, aspectos do domínio de cada competência, para sua valorização. Para promover a cooperação internacional entre todo tipo de bibliotecas e desenvolver programas, a ALFIN e a IFLA apresentam normas para a alfabetização informacional, apontando três aspectos básicos interrelacionados - acesso, avaliação e uso - para que os usuários possam constituir-se em aprendizes de fato da informação.

A alfabetização informacional, de acordo com os padrões da AASL, engloba três tipos de conhecimento e habilidades: para encontrar a informação (localização e recuperação documental e bibliográfica; manejo de ferramentas tecnológicas e manejo de fontes de informação); para usar a informação (habilidades de pensamento, estudo e investigação, produção e apresentação); para partilhar e atuar eticamente com respeito à informação. 
De maneira similar, as normas de alfabetização profissional da IFLA, baseadas em experiências e contribuições internacionais indicam os seguintes aspectos básicos, que interrelacionados permitem aos usuários constituir-se em aprendizes efetivos da informação: acesso (o usuário acesa a informação de forma efetiva e eficiente); avaliação (o usuário avalia a informação crítica e competentemente); uso (o usuário aplica/usa informação de forma precisa e criativa).

A noção de competência para Perrenoud (2000, p. 26) designa a capacidade de mobilizar recursos cognitivos para enfrentar diferentes situações, lidar com as características da sociedade atual, que tem como pilares fundamentais a informação e o conhecimento, cabendo aos profissionais que lidam com informação a responsabilidade de buscar novos instrumentos para preparar e integrar os sujeitos à tecnologia e aos ambientes virtuais, o que requer novas aprendizagens e estratégias.

A ALFIN/EEES (2005) classifica as competências em:

a) competência tecnológica - ocupa-se da teoria e da prática do formato, desenvolvimento, seleção e utilização, avaliação e gestão dos recursos tecnológicos, atendendo' aos seguintes aspectos: conhecimentos científicos teóricos das TICs e meios de comunicação; habilidades de manejo; alfabetização audiovisual; alfabetização informática e telemática; valorização do impacto das TICs e dos meios de comunicação de massa na sociedade e na educação; conhecimento dos materiais disponíveis no mercado: meios de comunicação de massa, vídeos, software, espaços web e avaliação da qualidade técnica, pedagógica e funcional; conhecimento das possíveis aplicações em educação; planejamento, gestão e avaliação de atividades educativas com apoio tecnológico; delineamento de desenvolvimento de materiais educativos em suporte tecnológico; organização dos recursos pedagógicos centrais (ALFIN/EEES, 2005).

b) competência informacional, chamada também de educação em informação ou alfabetização informacional é um processo de aprendizagem, que se centra em três momentos: busca da informação - habilidades de localizar e recuperar documentos e de manejar equipamentos tecnológicos; Uso da informação habilidades de pensar, de estudar e investigar; Disseminação da informação habilidades de produzir e de representar (ALFIN/EEES, 2005). 
As competências tecnológica e informacional exigem um mínimo de habilidades para o pleno sucesso educativo no uso da Internet: utilizar as principais ferramentas de Internet; conhecer as características básicas de equipamentos e infraestruturas informáticas necessários para acessar a Internet; diagnosticar a informação da qual se necessita; encontrar a informação que se busca e recuperá-la com agilidade; avaliar a qualidade, autenticidade e atualidade da informação que se queira, considerando alguns indicadores; avaliar a idoneidade da informação obtida para ser utilizada em cada situação concreta; aproveitar as possibilidades de comunicação que a Internet oferece; avaliar a eficácia e eficiência da metodologia empregada na busca de informação e na comunicação através da Internet. (ALFIN/EEES, 2005).

Nesta perspectiva de desenvolvimento de competências informacionais, a ALFIN/EEES apresenta em seu portal o movimento da Pedagogia Informacional: ensinar a aprender na Sociedade da Informação, centrado na hipótese educativa - ensinar a aprender, e, sobretudo, utilizar adequadamente a informação no processo ensino e aprendizagem, o que demanda nova arquitetura de estratégias, focada na aprendizagem para a vida.

O propósito da Pedagogia Informacional é preparar docentes e estudantes para exercer o papel de mediadores da informação, buscando reciprocidade, significado e transcendência desta informação, percorrendo o fluxo de um processo cognitivo nas dimensões de acesso, análise, interpretação, avaliação, produção etc., fechando o ciclo informacional e pedagógico - a informação como ponto de saída e de entrada. Nesta direção, a pedagogia informacional cria as condições para o verdadeiro diálogo entre o usuário-leitor e o ambiente informacional, construindo aprendizagens significativas, por meio de metodologias inovadoras.

Deste modo, a Pedagogia Informacional teria função expressiva no delineamento do modelo de biblioteca 2.0 subsidiando a criação de serviços informacionais interativos, dinâmicos e partilhados e na capacitação de usuários na busca e uso da informação, constituindo-se numa rede social potencializadora da participação ativa dos usuários, a inteligência coletiva e o trabalho colaborativo, fortalecendo a missão da instituição biblioteca e dos profissionais que nela atuam.

Em contrapartida às exigências das competências informacionais e digitais, o documento da ALFIN/EEES ressalta que, desde Paulo Freire até nossos dias, o avanço e a inovação em matéria pedagógica foi relativamente lento, levando em consideração a dinamicidade científica em outras áreas. Na visão de Freire (1980), “alfabetizar é conscientizar", é "um aprender a escrever sua vida, como autor e como testemunha de sua 
história". Este pressuposto continua tão atual quanto em qualquer tempo em que seja aplicado, pois o que se espera da educação é a conscientização do sujeito - de ser e de estar na sociedade em que vive. $\mathrm{Na}$ atualidade, pode-se visualizar este pressuposto pela imperiosa necessidade de tomar consciência das coordenadas da sociedade do conhecimento, além das tarefas de criar, administrar, selecionar, processar e difundir a informação, como uma ferramenta fundamental para o desenvolvimento humano.

O Informe "Habilidades e Competências do Século XXI para os Aprendizes do Novo Milênio nos Países da OCDE" tema de congresso internacional sobre as competências do século XXI em Bruxelas, realizado em 2009, objetivou propor uma tipologia de agrupação de habilidades e competências nas categorias que se seguem: habilidades funcionais TIC e habilidades TIC para aprender, que incluem habilidades cognitivas de ordem superior com habilidades funcionais para uso e manejo destas aplicações, isto porque a grande quantidade de informação disponível na Internet e a proliferação de base de dados exige encontrar e organizar rapidamente a informação e desenvolver certa habilidade de discriminação da informação, de fato o conceito de alfabetização se centra neste processo, (ANDERSON, 2008) e pressupõe que um estudante entenda primeiro e logo defina claramente a informação que seja a base de uma tarefa determinada.

Saber como identificar digitalmente as fontes de informação relevantes e saber como buscar e selecionar a informação requer considerar, de modo efetivo e eficiente, como deve ser solucionado um problema; uma vez que a informação foi localizada é fundamental que o estudante seja capaz de avaliar quão útil e valiosa é a fonte e seus componentes para uma tarefa determinada, assim como ser capaz de armazenar e organizar dados e informações digitais eficazmente de modo que possa voltar a usá-la. Apresenta-se como exemplo de habilidades e competências, a alfabetização em informação e meios, a investigação e a indagação. Isto significa obter a informação como produto, ou seja, a reestruturação e modelagem da informação e o desenvolvimento de ideias próprias sobre o conhecimento.

Cabe, portanto, à educação superior, cumprir com a formação de profissionais que contribuam para melhorar a qualidade de vida dos membros da sociedade, planejando ações que integrem as mudanças que se apresentam com os avanços do conhecimento, da ciência e da tecnologia. Nesse contexto, recrutam-se pessoas formadas que atendam às habilidades do desenvolvimento da leitura. Não de uma leitura vista sob a ótica da psicolingüística ou da sociolingüística e, sim, de uma perspectiva social e cultural. 


\section{CONSIDERAÇÕES FINAIS}

A partir das reflexões apresentadas neste artigo pode-se observar as transversalidades políticas, conceituais, estruturais, processuais e metodológicas incidentes sobre o campo da informação, com destaque para a interlocução entre a ciência da informação, a educação e a cognição.

Contemplando a variável sociopolítica dos modelos informacionais, conclui-se que apropriar-se da informação pertinente, útil e oportuna na sociedade intelectualizada e competitiva em que se vive nos dias atuais é, para o sujeito, não, apenas, mera questão de sobrevivência, mas uma condição decisiva para a autonomia e vivência plena da cidadania.

Neste aspecto, há que se observar a capacidade que tem o sujeito de lidar com os fluxos informacionais e de transformar a informação apreendida em conhecimento, alimentando o processo de tomada de decisão, de inovação e criatividade, gerando novos produtos e serviços culturais, científicos, tecnológicos, econômicos, políticos etc., de valor para a sociedade.

Ademais, a criação, implantação e mudanças constantes nos dispositivos, artefatos e infraestrutura de informação - tais como bibliotecas, bibliotecas virtuais e digitais, sistemas de informação, computadores e tecnologias associadas, bases de dados etc. - reconfiguram continuamente os modelos de comunicação, a exemplo da plataforma web 2.0, que proporciona possibilidades variadas de acesso e intercâmbio de informações entre os diversos atores sociais, que produzem, usam e gerem a informação, exigindo interpretação e compreensão deste complexo diálogo que se realiza nestas redes sociocomunicacionais.

Do ponto de vista objetivo, no âmbito das práticas informacionais e de sua interlocução com a educação e as ciências cognitivas, depreende-se que a busca e o uso da informação, em todas as dimensões - acesso, análise, interpretação, avaliação, produção, entre outros - subentende o domínio de competências e habilidades específicas e inerentes, bem como o domínio da leitura e seu significado crítico, sendo todas estas categorias mentais integrantes da ação cognitiva.

Nesta perspectiva, as bibliotecas têm adotado, como linha de gestão, a premissa da abordagem centrada no usuário, que toma como ponto de referência, para suas decisões, ações e serviços, as necessidades e expectativas do usuário e da comunidade onde estão inseridas, pressupondo a necessidade de focar os aspectos cognitivos que subjazem ao processo de 
busca e uso da informação, considerando, também, as experiências individuais e a criatividade do sujeito.

Fica, assim, evidenciado o significado dos estudos pedagógicos - ensino, aprendizagem, estratégias didáticas e mediação - para lidar com os usuários e, em tese, capacitá-los para buscar e usar a informação, uma vez que, neste paradigma, o que se pretende é que este se torne autônomo e independente, além de ser consciente da importância e valor das informações, como recurso que permite o desenvolvimento de pessoas na sua vida profissional, acadêmica e cotidiana.

Por sua vez, de modo recíproco, os estudos pedagógicos aportarão fundamentos e metodologias que subsidiarão as ações do formador de usuários e a relação entre estes atores.

De modo efetivo e sistemático, uma resposta a esta questão da capacitação do usuário para lidar com a informação é a implantação e operacionalização do Programa ALFIN/EEES, concebido pelo Espaço Europeu de Educação Superior, mas agora presente em diversos espaços, inclusive em alguns países da América Latina, cujo escopo é ensinar a aprender e a usar com propriedade a informação no processo ensino aprendizagem, aplicando ferramentas e técnicas que levem ao desenvolvimentos de habilidades de informação, fomentando valores como a inovação, a criatividade, o trabalho em equipe e a aprendizagem permanente.

\section{REFERÊNCIAS}

ALFIN/EEES. Habilidades e competencias de gestión da información para aprender a aprender en el marco del espacio europeo de enseñanza superior. España. Universidade de Granada, 2005. Disponível em: <http://www.um.es/dp-lenguaespa/.../habilidadescompetencias. pdf>. Acesso em: 15 out. 2009.

AUSUBEL, D. P. Educational Psychology: a cognitive view. New York: Holt, Rinehart and Winston, 1978.

AXT, M. Estudos cognitivos: mapeando tendências. In: SILVA, D. F. da, VIEIRA, R. (Org.). Ciências Cognitivas em Semiótica e Comunicação. São Leopoldo, RS: Editora da UNISINOS, 1999. p. 67-92.

BROOKES, B. C. The forms of information science: part 1. Philosophical aspects. Journal of Information Science, v.2, n.3/3, p.125-133, out. 1980.

DEL NERO, H. S. O sítio da mente: pensamento, emoção e vontade no cérebro humano. São Paulo: Collegium Cognitio, 1997.

DERVIN, B. Information needs and uses. Annual review of information science an technology, New York, v. 21, p. 3-33, 1986. 
DUCROT, O. O dizer e o dito. Campinas: Pontes Editores, 1987.

FÁVERO, M. H. Psicologia e conhecimento: subsídios para a análise do ensinar e aprender. Brasília: EDUnB. 2005.

Os fundamentos teóricos e metodológicos da psicologia do conhecimento. In: FÁVERO, M. H. \& CUNHA, C. (Coord.). Psicologia do Conhecimento. O diálogo entre as ciências e a cidadania. Brasília: UNESCO, 2008.

FEUERSTEIN, R. Instrumental enrichment: an intervention program for cognitive modifiability. Baltimore: University Park Press, 1980.

FLAVELL, J. H. Cognitive development. New Jersey: Prentice Hall, 1985.

FREIRE, P. Educação e mudança. Rio de Janeiro: Paz e Terra, 1979.

FREIRE, P. Conscientização: teoria e prática da libertação. Uma introdução ao pensamento de Paulo Freire. São Paulo: Moraes, 1980.

Extensão ou comunicação. Rio de Janeiro: Paz e Terra, 1985.

Pedagogia do oprimido. 32. ed. Rio de Janeiro: Paz e Terra, 2002.

GONZÁLEZ DE GÓMEZ, M. N. Novos cenários políticos para a informação. Ciência da Informação, Brasília, v. 31, n. 1, p. 27-40, jan./abr. 2002.

HJØRLAND, B. Toward a new horizon in information science: domain analysis. Journal of American Society for Information Science. v. 46, n. 6, p. 400-425, 1995.

JAPIASSÚ, H. Interdisciplinaridade e patologia do saber. Rio de Janeiro: Imago, 221p. 1975.

KUHLTHAU, C. C. The Concept of a zone of intervention for identifying the role of intermediaries in the information search process. New Brunswick, NJ: Rutgers University, 1996. Disponível em: <http://mail.asis.org/annual-96/electronic proceedings/kuhlthau.html > Acesso: 30 mar. 2010.

Information skills for an information society: a review of research. Syracuse. NY: ERIC Clearinghouse on information resources, 1987.

Inside the search process: information seeking from the use perspective. Journal of the American Society for Information Science. v. 42, n. 5, p.361-371, 1991.

OECD. Habilidades y competencias del siglo XXI para los aprendices del neuvo milenio en los países de la OCDE. España. Ministerio de Educación, Cultura y Deporte. Instituto de Tecnologías Educativas. 2006. Disponível em: <www.ite.educación.es $>$. Acesso em: 21 de fev 2012. 
PERRENOUD, P. Dez novas competências para ensinar. Translated by Patrícia Chittoni Ramos. Porto Alegre: Artes Médicas Sul. 2000.

PIAGET, J. A epistemologia genética. Petrópolis : Vozes, 1971.

. Psicologia e pedagogia. Rio de Janeiro: Forense, 1970.

. O nascimento da inteligência na criança. Suiça: Editora Guanabara. 1987

.; INHELDER, B. A psicologia da criança. São Paulo: Difusão, 1986.

POZO, J. I.. Aquisição de conhecimento. Trad. de Feltrin. Porto Alegre: Artes

Médicas. 2005.

ROZADOS, H. B. F. A Ciência da Informação em sua aproximação com as ciências cognitivas. Em Questão, Porto Alegre, v. 9, n. 1, p. 79-94, jan./jun. 2003.

SKINNER, B. F. The Shaping of a Behaviorist. New York; Alfred A. Knopf, 1979.

VAN DIJK, T. Cognição, discurso e interação. São Paulo: Contexto, 1996.

VYGOTSKY, L. S. A formação social da mente. São Paulo: Martins Fontes, 1984.

A formação social da mente. São Paulo: Martins Fontes, 1991. 